\title{
Contribution of Matrix Metalloproteinase-7 Genotypes to the Risk of Non-solid Tumor, Childhood Leukemia
}

\author{
JEN-SHENG PEI $^{1 *}$, AN-KUO CHOU $^{2,3 *}$, PEI-CHEN HSU ${ }^{1 *}$, CHIA-WEN TSAI $^{3}$, WEN-SHIN CHANG ${ }^{3}$, \\ MENG-FENG WU ${ }^{3}$, MING-HSIEN WU ${ }^{3}$, TE-CHUN HSIA ${ }^{3}$, SHUN-PING CHENG ${ }^{5}$ and DA-TIAN BAU ${ }^{3,4,6}$ \\ Departments of ${ }^{1}$ Pediatrics and ${ }^{5}$ Physical Medicine and Rehabilitation, \\ Taoyuan General Hospital, Ministry of Health and Welfare, Taoyuan, Taiwan, R.O.C.; \\ ${ }^{2}$ Department of Anesthesiology, and ${ }^{3}$ Terry Fox Cancer Research Laboratory, \\ China Medical University Hospital, Taichung, Taiwan, R.O.C.; \\ ${ }^{4}$ Graduate Institute of Biomedical Sciences, China Medical University, Taichung, Taiwan, R.O.C.; \\ ${ }^{6}$ Department of Bioinformatics and Medical Engineering, Asia University, Taichung, Taiwan, R.O.C.
}

\begin{abstract}
Background/Aim: The matrix metalloproteinases (MMPs) are important in inflammation and carcinogenesis, and the genotypic role of MMP7 has never been examined in leukemia to date. Therefore, in this study we aimed to evaluate the contribution of the genotypic variants in the promoter region of $M M P 7(A-181 G$ and $C-153 T)$ to childhood acute lymphoblastic leukemia (ALL) risk in Taiwan. Materials and Methods: In this case-control study, 266 patients with childhood ALL and 266 non-cancer controls were genotyped by polymerase chain reactionrestriction fragment length polymorphism methodology. Results: The distribution of $A A, A G$ and $G G$ for $M M P 7$ promoter $A-181 G$ genotype was $83.5,12.0$ and $4.5 \%$ in the childhood ALL group and 89.8\%, 9.4 and $0.8 \%$ in the noncancer control group, respectively ( $p$ for trend=0.0134), significantly differentially distributed between childhood ALL and control groups. The comparisons in allelic frequency distribution also support the findings that $G$ appears to be the risky allele in childhood ALL. In genotype and gender interaction analysis, it was found that boys carrying the $M M P 7 A-181 G G G$ and $A G+G G$ genotypes had 9.05- and 2.45-fold odds ratios (ORs) ( $p=0.0135$ and 0.0142, respectively) for childhood ALL compared to those carrying
\end{abstract}

\footnotetext{
*These Authors contributed equally to this work.

Correspondence to: Da-Tian Bau, Terry Fox Cancer Research Laboratory, Department of Medical Research, China Medical University Hospital, 2 Yuh-Der Road, Taichung, 404 Taiwan, R.O.C. Tel: +886 422053366 Ext. 5805, e-mail: datian@mail.cmuh.org.tw; artbau2@gmail.com
}

Key Words: Childhood leukemia, MMP7, genotype, polymorphism, Taiwan. wild-type AA genotype. But these differences were not found in girls. Analysis of genotype interaction with age of onset age showed those aged less than 3.5 years at onset carrying the $G G$ or $A G+G G$ genotypes also had elevated ORs of 8.79- and 2.04-fold ( $p=0.0150$ and 0.0413, respectively) for childhood ALL, but there was no such difference for those having an age at onset of 3.5 years or more. Conclusion: Our results indicate that the MMP7 A-181G genotype interacts with age and gender and may serve as an early and predictive biomarker for childhood ALL.

Matrix metalloproteinases (MMPs), also known as matrixins, are a family of zinc-dependent endopeptidases playing a key role in extracellular matrix (ECM) homeostasis by their degradation of various connective tissue matrices $(1,2)$. The imbalances of the capacity of MMPs and their specific inhibitors, i.e. the tissue inhibitors of metalloproteinases (TIMPs) are closely related to the processes of inflammation, carcinogenesis and migration (2-4). In the early 1990s, evidence showed that the overexpression of MMPs in tumor and stromal cells in various cancer types was associated with invasion and progression of tumorigenesis (5). In addition, MMPs released from distant organs, together with growth factors from tumor cells, can participate in pre-metastatic niche formation and metastasis $(6,7)$. Furthermore, elevated expression of MMP3 and MMP7 in Helicobacter pylorirelated gastric cancer were reported to serve as biomarkers for poor survival (8).

MMP7 has also been shown to be produced constitutively by exocrine glands, including the mammary and parotid glands, the pancreas, liver, prostate and peribronchial glands of the lung (9). In the literature, there is mounting evidence indicating that functional polymorphisms of MMPs may contribute to inter-individual differences in susceptibility to several types of cancer (10-19). In a promoter assay, the 
basal promoter activity was higher in promoter constructs harboring the combination of the two rare alleles of $M M P 7$ at A-181G (rs11568818) and C-153T (rs11568819) (20), and these two polymorphisms were reported to influence the dimensions of the coronary artery (20). In cancer genomic association studies, the A-181G genotype of MMP7 was reported to be associated with many types of cancer, including oral, esophageal, gastric, colorectal, lung, breast, ovarian cancer (21), but not renal cell carcinoma (22).

The genomic contribution of MMP7 to ALL has not been well elucidated, let alone in childhood ALL. The purpose of this study was to reveal the contribution of MMP7 genotype at the promoter A-181G site to the risk of ALL in a representative pediatric population sample (controls/cases=266/266) of Taiwanese children.

\section{Materials and Methods}

Investigated population and sample collection. Our study was approved by the Institutional Review Board of China Medical University Hospital, and written informed consent was obtained from one or both parents of all participants. Two hundred and sixtysix patients diagnosed with childhood ALL (all patients under 18 years of age) were recruited between 2005-2010 from the General Surgery outpatient clinics within the Pediatric Departments at the China Medical University Hospital and the National Taiwan University Hospital, Taiwan, Republic of China. All of the clinical characteristics of these patients, including their histological details, were identified by expert surgeons. All children voluntarily participated, completed a questionnaire with the help of parents or guardians, and provided peripheral blood samples. The questionnaire recorded their disease history, diet and sleeping habit, and the disease history, diet, behavioral lifestyle and socialeconomic status of the parents. An equal number of age-matched non-cancer healthy volunteers were selected for use as a control group following initial random sampling from the Health Examination Cohort established from 2005 to 2010 as previously published (23-26). The registered health practitioners in the hospital provide a multidisciplinary team approach of health assessment for the volunteers. Most of the volunteers underwent health examinations every 5 to 6 months. A total of 457 volunteers aged under 18 years were recruited into this study were cancer free by the age at diagnosis of the matched-case child with the International Classification of Disease, ninth revision (ICD-9) codes (defined by the World Health Organization) (24). Finally, 266 participants were included for analysis in the study in order to match the population structure (number, age and gender) of our case population. The overall agreement rate in the study was above $85 \%$.

Genotyping methodology. Genomic DNA was prepared from peripheral blood leukocytes using a QIAamp Blood Mini Kit (Blossom, Taipei, Taiwan), stored long-term at $-80^{\circ} \mathrm{C}$, diluted and aliquoted for genotyping as a working stock at $-20^{\circ} \mathrm{C}(27,28)$. The sequences of primers and the restriction enzymes for $M M P 7$ genotyping are the same as our recently published genotyping methodology (22). Briefly, the polymerase chain reaction (PCR) cycling conditions were: one cycle at $94^{\circ} \mathrm{C}$ for $5 \mathrm{~min} ; 35$ cycles of $94^{\circ} \mathrm{C}$ for $30 \mathrm{~s}, 59^{\circ} \mathrm{C}$ for $30 \mathrm{~s}$ and $72^{\circ} \mathrm{C}$ for $30 \mathrm{~s}$, and a final extension at $72^{\circ} \mathrm{C}$ for $10 \mathrm{~min}$. The PCR for MMP7 A-181G was conducted using the forward primer 5'-TGGTACCATAATGTCCTGAATG-3', and the reverse primer 5'-TCGTTATTGGCAGGAAGCACAC AATGAATT-3'. The obtained 150-bp PCR product was digested with EcoRI and resulted in two fragments of 120 and $30 \mathrm{bp}$ when the $\mathrm{G}$ allele was present, while in the presence of the A allele, the $150 \mathrm{bp}$ fragment remained intact. For MMP7 C-153T, direct sequencing PCR was conducted with the same primers as for $M M P 7 \mathrm{~A}-181 \mathrm{G}$. After amplification, the PCR products were subject to digestion and separation using 3\% agarose gel electrophoresis. All the genotypic processing was repeated by two researchers independently, and blindly, and the results were $100 \%$ concordant. In addition, the success rate of PCR-restrictive fragment length polymorphism (RFLP) is $100 \%$, and the genotypes of $5 \%$ of the participants in both the control and patient groups were analyzed by PCR direct sequencing (Genomics BioSci \& Tech Co., Taipei, Taiwan). The concordance between direct sequencing and PCR-RFLP was $100 \%$.

Statistical analyses. Those participants having both genotypic and clinical data (controls/cases=266/266) were selected for final analysis. The descriptive statistics of patients and controls are presented as the mean and standard deviation (SD) or as percentages. The Pearson's chi-square test or Fisher's exact test (when any cell was less than five) was used to compare the distribution of the genotypes. Associations were evaluated as odds ratios (ORs) with $95 \%$ confidence intervals (CIs). Statistical tests were deemed significant when the $p$-value was less than 0.05 .

\section{Results}

Comparison of demographics between the childhood ALL and control groups. The frequency distributions for the age and gender of 266 patients with childhood ALL and 266 noncancer healthy controls are shown in Table I. The data showed that the age and gender of the cases and controls were both well-matched between the childhood ALL and 266 non-cancer healthy control groups ( $>>0.05$ ) (Table I).

Association of MMP7 promoter genotypes and childhood $A L L$ risk. The genotypic analysis for the MMP7 A-181G and C153T among the controls and patients are shown and compared in Table II. The data show that there was no polymorphic genotypes among this Taiwanese population at MMP7 C-153T (Table II, lower panel). The genotypic frequency distributions for MMP7 A-181G were significantly different between childhood ALL and control groups ( $p$ for trend $=0.0134$ ) (Table II, upper panel). In detail, the MMP7 A-181G heterozygous AG and homozygous GG were associated with increased risk of childhood ALL ( $p=0.2553$ and 0.0056 , adjusted $\mathrm{OR}=1.42$ and $6.83,95 \% \mathrm{CI}=0.84-2.13$ and 1.76-20.33, respectively; Table II). Combining the homozygotes and heterozygotes for the $\mathrm{G}$ allele $(\mathrm{AG}+\mathrm{GG})$ showed that the $\mathrm{G}$ allele at MMP7 A-181G conferred an increased risk for childhood ALL of 1.95-fold $(p=0.0302)$ (Table II). Overall, MMP7 A-181G seems to be useful genotypic marker for early detection and prediction of increased risk for childhood ALL in Taiwanese. 
Table I. Demographic information of 266 childhood acute lymphoblastic leukemia cases and 266 matched controls.

\begin{tabular}{|c|c|c|c|c|c|c|c|}
\hline \multirow[t]{2}{*}{ Characteristic } & \multicolumn{3}{|c|}{ Controls $(\mathrm{n}=266)$} & \multicolumn{3}{|c|}{ Cases $(n=266)$} & \multirow[t]{2}{*}{$p$-Value } \\
\hline & $\mathrm{n}$ & $\%$ & Mean (SD) & $\mathrm{n}$ & $\%$ & Mean (SD) & \\
\hline Age at onset & & & $8.3(4.8)$ & & & $7.0(4.4)$ & $0.64^{\mathrm{a}}$ \\
\hline$<3.5$ years & 133 & $50.0 \%$ & & 133 & $50.0 \%$ & & \\
\hline$\geq 3.5$ years & 133 & $50.0 \%$ & & 133 & $50.0 \%$ & & $1.00^{\mathrm{b}}$ \\
\hline \multicolumn{8}{|l|}{ Gender } \\
\hline Male & 148 & $55.6 \%$ & & 148 & $55.6 \%$ & & \\
\hline Female & 118 & $44.4 \%$ & & 118 & $44.4 \%$ & & $1.00^{\mathrm{b}}$ \\
\hline
\end{tabular}

aBased on Student's $t$-test; b based on Chi-square test.

Association of MMP7 promoter allelic frequencies and childhood ALL risk. The distributions of allelic frequencies for MMP7 A-181G and C-153T polymorphisms among the patients and the controls are shown in Table III. Consistent with the findings in Table II, G allele at MMP7 A-181G was significantly associated with increased childhood ALL risk $(p=0.0023$ and adjusted $\mathrm{OR}=2.13)$ (Table III).

Stratified analysis of MMP7 genotypes according to age and gender. Because age and gender are the predominant risk factors for developing childhood ALL, the contribution of the MMP7 A-181G genotype to childhood ALL stratified by age and gender were further analyzed and the results are presented in Table IV. The average median age of onset of ALL in the patient groups was 3.5 years; thus, we further stratified the groups into subgroups of those aged less than 3.5 years and 3.5 years old or more. Notably, in the younger (age of onset $<3.5$ years old) sub-group, those with $G$ allele-bearing genotypes for MMP7 A-181G had higher risk for developing childhood ALL than those with the wild-type AA genotype ( $p$ for trend $=0.0184, p=0.0135$ and $0.0142 ; \mathrm{OR}=9.05$ and 2.45, 95\% $\mathrm{CI}=1.11-73.52$ and 1.18-5.09 for $\mathrm{GG}$ and $\mathrm{AG}+\mathrm{GG}$, respectively); on the contrary, there was no significant association found in the analysis of the older (age of onset $\geq 3.5$ years old) sub-group (Table IV, upper panel). Regarding gender, males carrying a $\mathrm{G}$ allele for $M M P 7 \mathrm{~A}$ $181 \mathrm{G}$ were more likely to develop childhood ALL than those with the homozygous AA genotype ( $p$ for trend $=0.0332, p=0.0150$ and $0.0413, \mathrm{OR}=8.79$ and 2.04, 95\% $\mathrm{CI}=1.08-71.28$ and 1.02-4.09 for $\mathrm{GG}$ and $\mathrm{AG}+\mathrm{GG}$, respectively). On the contrary, there was no significant association found in the analysis of the female sub-group (Table IV, lower panel).

In summary, the results of stratification analysis revealed an interaction between younger age at onset and being male with $M M P 7$ A-181G genotype in susceptibility to childhood ALL in Taiwanese.
Table II. Distributions of matrix metalloproteinase-7 A-181G and C-153T genotypic frequencies among the childhood acute lymphoblastic leukemia cases and controls.

\begin{tabular}{lcccc}
\hline & $\begin{array}{c}\text { Cases, } \\
\mathrm{n}(\%)\end{array}$ & $\begin{array}{c}\text { Controls, } \\
\mathrm{n}(\%)\end{array}$ & $\begin{array}{c}\text { Adjusted OR } \\
(95 \% \mathrm{CI})^{\mathrm{a}}\end{array}$ & $p$-Value $^{\mathrm{b}}$ \\
\hline $\mathrm{A}-181 \mathrm{G}$ & & & & \\
$\mathrm{AA}$ & $222(83.5)$ & $239(89.8)$ & 1.00 (Reference) & \\
AG & $32(12.0)$ & $25(9.4)$ & $1.42(0.84-2.13)$ & 0.2553 \\
GG & $12(4.5)$ & $2(0.8)$ & $6.83(1.76-20.33)$ & $0.0056^{*}$ \\
AG+GG & $44(16.5)$ & $27(10.2)$ & $1.95(1.24-2.78)$ & $0.0302^{*}$ \\
$p_{\text {trend }}$ & & & & $0.0134^{*}$ \\
$\mathrm{C}-153 \mathrm{~T}$ & & & & \\
CC & $266(100.0)$ & $266(100.0)$ & 1.00 (Reference) & \\
CT & $0(0.0)$ & $0(0.0)$ & -- & \\
TT & $0(0.0)$ & $0(0.0)$ & -- & \\
$p_{\text {trend }}$ & & & & \\
\hline
\end{tabular}

OR, Odds ratio; CI, confidence interval. aData have been adjusted for confounding factors age and gender. ${ }^{\mathrm{b}} \mathrm{Based}$ on chi-square test without Yates' correction (in case of any compared cell less than 5). *Statistically significant.

Table III. Allelic frequencies for matrix metalloproteinase-7 A-181G and C-153T polymorphisms among the childhood acute lymphoblastic leukemia cases.

\begin{tabular}{ccccc}
\hline Allelic type & $\begin{array}{c}\text { Cases, } \\
\mathrm{n}(\%) \\
\mathrm{N}=532\end{array}$ & $\begin{array}{c}\text { Controls, } \\
\mathrm{n}(\%) \\
\mathrm{N}=532\end{array}$ & $\begin{array}{c}\text { Adjusted OR } \\
(95 \% \mathrm{CI})^{\mathrm{a}}\end{array}$ & $p$-Value \\
\hline A-181G & & & & \\
Allele A & $476(89.5)$ & $503(94.5)$ & 1.00 (Reference) & $0.0023^{*}$ \\
Allele G & $56(10.5)$ & $29(5.5)$ & $2.13(1.43-2.98)$ & \\
C-153T & & & & \\
Allele C & $532(100.0)$ & $532(100.0)$ & 1.00 (Reference) & - \\
Allele T & $0(0.0)$ & $0(0.0)$ & -- & \\
\hline
\end{tabular}

OR, Odds ratio; CI, confidence interval. aData have been adjusted for confounding factors age and gender. bBased on chi-square test without Yates' correction. *Statistically significant. 
Table IV. Distribution of the matrix metalloproteinase-7 A-181G genotypes stratified by age and gender among 266 childhood acute lymphoblastic leukemia cases and 266 healthy controls.

\begin{tabular}{|c|c|c|c|c|c|}
\hline \multirow[b]{2}{*}{ Characteristics } & \multicolumn{3}{|c|}{$M M P 7 \mathrm{~A}-181 \mathrm{G}$} & \multirow[b]{2}{*}{$p$-Value ${ }^{a}$} & \multirow[b]{2}{*}{ OR $(95 \% \mathrm{CI})$} \\
\hline & $\begin{array}{l}\text { Cases } \\
\mathrm{n}(\%)\end{array}$ & $\begin{array}{c}\text { Controls } \\
\mathrm{n}(\%)\end{array}$ & $p_{\text {trend }}{ }^{\mathrm{a}}$ & & \\
\hline \multicolumn{6}{|l|}{ Age at onset } \\
\hline$<3.5$ years & & & $0.0184^{*}$ & & \\
\hline $\mathrm{AA}$ & $107(80.5)$ & $121(91.0)$ & & & 1.00 (Reference) \\
\hline $\mathrm{AG}$ & $18(13.5)$ & $11(8.3)$ & & 0.1245 & $1.85(0.84-4.09)$ \\
\hline GG & $8(6.0)$ & $1(0.7)$ & & $0.0135^{*}$ & $9.05(1.11-73.52)$ \\
\hline $\mathrm{AG}+\mathrm{GG}$ & $26(19.5)$ & $12(9.0)$ & & $0.0142 *$ & $2.45(1.18-5.09)$ \\
\hline$\geq 3.5$ years & & & 0.3988 & & \\
\hline $\mathrm{AA}$ & $115(86.5)$ & $118(88.7)$ & & & 1.00 (Reference) \\
\hline $\mathrm{AG}$ & $14(10.5)$ & $14(10.5)$ & & 0.9487 & $1.02(0.47-2.25)$ \\
\hline GG & $4(3.0)$ & $1(0.8)$ & & 0.1751 & $4.10(0.45-37.28)$ \\
\hline $\mathrm{AG}+\mathrm{GG}$ & $18(13.5)$ & $15(11.3)$ & & 0.5769 & $1.23(0.59-2.56)$ \\
\hline \multicolumn{6}{|l|}{ Gender } \\
\hline Male & & & $0.0332 *$ & & \\
\hline AA & $122(82.4)$ & $134(90.5)$ & & & 1.00 (Reference) \\
\hline AG & $18(12.2)$ & $13(8.8)$ & & 0.2735 & $1.52(0.72-3.23)$ \\
\hline GG & $8(5.4)$ & $1(0.7)$ & & $0.0150 *$ & $8.79(1.08-71.28)$ \\
\hline $\mathrm{AG}+\mathrm{GG}$ & $26(17.6)$ & $14(9.5)$ & & $0.0413^{*}$ & $2.04(1.02-4.09)$ \\
\hline Female & & & 0.3542 & & \\
\hline $\mathrm{AA}$ & $100(84.8)$ & $105(89.0)$ & & & 1.00 (Reference) \\
\hline AG & $14(11.8)$ & $12(10.2)$ & & 0.6265 & $1.23(0.54-2.78)$ \\
\hline GG & $4(3.4)$ & $1(0.8)$ & & 0.1677 & $4.20(0.46-38.22)$ \\
\hline $\mathrm{AG}+\mathrm{GG}$ & $18(15.2)$ & $13(11.0)$ & & 0.3353 & $1.45(0.68-3.12)$ \\
\hline
\end{tabular}

OR, Odds ratio; CI, confidence interval. aBased on Chi-square test. *Statistically significant difference.

\section{Discussion}

In this investigation, we firstly examined the contribution of MMP7 genotype to childhood ALL susceptibility. Since MMP7 is a zinc-dependent endopeptidase in charge of degrading ECM macromolecules such as casein, type I, II, IV and V gelatins, fibronectins and proteoglycans (29), it is very possible that hereditary genomic variations may determine personal risk for inflammatory processes, carcinogenesis and cancer metastasis $(30,31)$. MMP7 is commonly expressed in ductal epithelium of exocrine glands in skin, salivary glands, pancreas, glandular epithelium of intestine and reproductive organ, liver, and breast, and is highly expressed in the luminal surface of dysplastic glands in human colorectal cancer (29). In clinical practice, MMP7 inhibitors can potentially be applied to control the invasive capacity of cancer cells $(30,32-34)$. In 2013, MMP7 was found to be highly expressed in advanced colorectal adenomatous and involved in converting colorectal adenomas into a malignant state and facilitating the cancer growth (35). In the literature, the A-181G genotype of MMP7 was studied for association with solid cancer such as oral, esophageal, gastric, colorectal, lung, breast and ovarian cancer, and renal cell carcinoma $(21,22)$. However, little is known about the contribution of $M M P 7$ genotypes to leukemia, which is a non-solid cancer. In the current study, we found that the GG homozygous genotype of MMP7 A-181G were significantly associated with an increased susceptibility to childhood ALL (Table II). As far as we are aware, the current study is the first to reveal the genotypic contribution of $M M P 7$ promoter genotypes to (childhood) ALL, with the novel findings that $\mathrm{G}$ allele at $M M P 7 \mathrm{~A}-181 \mathrm{G}$ may be a potential marker for prediction of childhood ALL (Tables II and III).

Furthermore, we analyzed the influence of the MMP7 A-181G genotype on childhood ALL susceptibility according to the age of onset and gender of the investigated children. Children in the early onset $(<3.5$ year-old) subgroup had a higher risk of childhood ALL with GG MMP7 A-181G genotypes than those with the wild-type AA genotype. However, this difference was not found for the older subgroup of children (Table IV). We also found that boys with GG genotypes at MMP7 A-181G were at higher risk of childhood ALL than those with the wild-type AA genotype. On the contrary, no statistically significant association was found in the analysis of MMP7 A-181G genotypes among girls (Table IV). Future investigation with a larger sample size may confirm the findings for the gender difference in the contribution of MMP7 A-181G genotype to ALL susceptibility 
among boys and girls. In the current study, it seems that the positive impact of the $\mathrm{G}$ allele at MMP7 A-181G with respect to ALL risk was more obvious for Taiwanese boys than girls (Table IV). In our previous findings, there was no significant association of renal cell carcinoma risk with MMP-7 A-181G genotype (22). In 2016, the A allele for flap endonuclease 1 rs174538 was found to be protective against childhood ALL, and the association was only significant for boys not girls (25). In searching for the different effects of sex hormones on leukemia cells, it was found that $17-\beta$ estrogen induced a significant increase of apoptosis in macrophage-like U937 cells, but testosterone did not (36). On the contrary, progesterone, but not $17-\beta$-estradiol, increased the secretion of tumor necrosis factor $\alpha$ in U937 cells, inducing the death of the cells by another pathway (37). The different influences of sexual hormones on the etiology of childhood ALL, and their interactions with genotypes need more investigations. Moreover, the international and inter-institute validation in larger populations regarding $M M P 7$ genotype and its phenotypic characteristics in all types of cancer are valuable for the understanding of the role of MMP7 in cancer development and prognosis.

In conclusion, this study provides genotypic evidence of a positive association between the genotype of $M M P 7 \mathrm{~A}-181 \mathrm{G}$ and childhood ALL. In addition, age and gender appear to interact with the $M M P 7 \mathrm{~A}-181 \mathrm{G}$ genotype in determining childhood ALL susceptibility. The presence of a $\mathrm{G}$ allele at MMP7 A-181G was not only a novel predictive biomarker for childhood ALL, but also a determinant for boys and patients younger than 3.5 years for higher risk for childhood ALL.

\section{Conflicts of Interest}

The Authors declare no conflicts of interest with any person or company interest in regard to this study.

\section{Acknowledgements}

This study was supported by research grants from Taoyuan General Hospital, Ministry of Health and Welfare, Taiwan, ROC to Dr. Pei (grant number: PTH10637) and the Taiwan Ministry of Health and Welfare Clinical Trial and Research Center of Excellence (MOHW106-TDU-B-212-113004). The technical assistance from Huai-Mei Hsu, Hsin-Ting Li and Shiou-Ting Yen is highly appreciated by the Authors.

\section{References}

1 Tishkoff DX, Filosi N, Gaida GM and Kolodner RD: A novel mutation avoidance mechanism dependent on S. cerevisiae $\operatorname{rad} 27$ is distinct from DNA mismatch repair. Cell 88: 253-263, 1997.

2 Parrish JZ, Yang C, Shen B and Xue D: CRN-1, a Caenorhabditis elegans fen-1 homologue, cooperates with CPS-6/EndoG to promote apoptotic DNA degradation. EMBO J 22: 3451-3460, 2003.
3 Lekstan A, Lampe P, Lewin-Kowalik J, Olakowski M, Jablonska B, Labuzek K, Jedrzejowska-Szypulka H, Olakowska E, Gorka D, Filip I and Dranka-Bojarowska D: Concentrations and activities of metalloproteinases 2 and 9 and their inhibitors (TIMPS) in chronic pancreatitis and pancreatic adenocarcinoma. J Physiol Pharmacol 63: 589-599, 2012.

4 Sternlicht MD and Werb Z: How matrix metalloproteinases regulate cell behavior. Annu Rev Cell Dev Biol 17: 463-516, 2001.

5 Monteagudo C, Merino MJ, San-Juan J, Liotta LA and StetlerStevenson WG: Immunohistochemical distribution of type IV collagenase in normal, benign, and malignant breast tissue. Am J Pathol 136: 585-592, 1990.

6 Bond M, Fabunmi RP, Baker AH and Newby AC: Synergistic up-regulation of metalloproteinase- 9 by growth factors and inflammatory cytokines: an absolute requirement for transcription factor NF-kappa B. FEBS Lett 435: 29-34, 1998.

7 Groblewska M, Mroczko B, Gryko M, Pryczynicz A, GuzinskaUstymowicz K, Kedra B, Kemona A and Szmitkowski M: Serum levels and tissue expression of matrix metalloproteinase 2 (MMP-2) and tissue inhibitor of metalloproteinases 2 (TIMP-2) in colorectal cancer patients. Tumour Biol 35: 3793-3802, 2014.

8 Yeh YC, Sheu BS, Cheng HC, Wang YL, Yang HB and Wu JJ: Elevated serum matrix metalloproteinase- 3 and -7 in $H$. pylorirelated gastric cancer can be biomarkers correlating with a poor survival. Dig Dis Sci 55: 1649-1657, 2010.

9 Saarialho-Kere UK, Crouch EC and Parks WC: Matrix metalloproteinase matrilysin is constitutively expressed in adult human exocrine epithelium. J Invest Dermatol 105: 190-196, 1995.

10 Tsai CW, Chang WS, Gong CL, Shih LC, Chen LY, Lin EY, Li $\mathrm{HT}$, Yen ST, Wu CN and Bau DT: Contribution of matrix metallopeptidase-1 genotypes, smoking, alcohol drinking and areca chewing to nasopharyngeal carcinoma susceptibility. Anticancer Res 36: 3335-3340, 2016.

11 Sun KT, Tsai CW, Chang WS, Shih LC, Chen LY, Tsai MH, Ji HX, Hsiao CL, Liu YC, Li CY and Bau DT: The contribution of matrix metalloproteinase-1 genotype to oral cancer susceptibility in Taiwan. In Vivo 30: 439-444, 2016.

12 Ye S: Polymorphism in matrix metalloproteinase gene promoters: implication in regulation of gene expression and susceptibility of various diseases. Matrix Biol 19: 623-629, 2000.

13 Price SJ, Greaves DR and Watkins H: Identification of novel, functional genetic variants in the human matrix metalloproteinase-2 gene: role of $\mathrm{Sp} 1$ in allele-specific transcriptional regulation. J Biol Chem 276: 7549-7558, 2001.

14 Yu C, Zhou Y, Miao X, Xiong P, Tan W and Lin D: Functional haplotypes in the promoter of matrix metalloproteinase-2 predict risk of the occurrence and metastasis of esophageal cancer. Cancer Res 64: 7622-7628, 2004.

15 Elander N, Soderkvist P and Fransen K: Matrix metalloproteinase (MMP)-1, -2, -3 and -9 promoter polymorphisms in colorectal cancer. Anticancer Res 26: 791-795, 2006.

16 Li Y, Jin X, Kang S, Wang Y, Du H, Zhang J, Guo W, Wang N and Fang S: Polymorphisms in the promoter regions of the matrix metalloproteinases-1, $-3,-7$, and -9 and the risk of epithelial ovarian cancer in China. Gynecol Oncol 101: 92-96, 2006.

17 Hu Z, Huo X, Lu D, Qian J, Zhou J, Chen Y, Xu L, Ma H, Zhu J, Wei $Q$ and Shen H: Functional polymorphisms of matrix metalloproteinase- 9 are associated with risk of occurrence and metastasis of lung cancer. Clin Cancer Res 11: 5433-5439, 2005. 
18 Shen TC, Hsia TC, Chao CY, Chen WC, Chen CY, Chen WC, Lin YT, Hsiao CL, Chang WS, Tsai CW and Bau DT: The contribution of $M M P 8$ promoter polymorphisms in lung cancer. Anticancer Res 37: 3563-3567, 2017.

19 Hung YW, Tsai CW, Wu CN, Shih LC, Chen YY, Liu YF, Hung HS, Shen MY, Chang WS and Bau DT: The contribution of matrix metalloproteinase- 8 promoter polymorphism to oral cancer susceptibility. In Vivo 31: 585-590, 2017.

20 Jormsjo S, Whatling C, Walter DH, Zeiher AM, Hamsten A and Eriksson P: Allele-specific regulation of matrix metalloproteinase7 promoter activity is associated with coronary artery luminal dimensions among hypercholesterolemic patients. Arterioscler Thromb Vasc Biol 21: 1834-1839, 2001.

21 Beeghly-Fadiel A, Shu XO, Long J, Li C, Cai Q, Cai H, Gao YT and Zheng W: Genetic polymorphisms in the $M M P 7$ gene and breast cancer survival. Int J Cancer 124: 208-214, 2009.

22 Liao CH, Chang WS, Hu PS, Wu HC, Hsu SW, Liu YF, Liu SP, Hung HS, Bau DT and Tsai CW: The contribution of $M M P 7$ promoter polymorphisms in renal cell carcinoma. In Vivo 31: 631-635, 2017.

23 Pei JS, Hsu PC, Chou AK, Tsai CW, Chang WS, Hsiao CL, Hsu YN, Cheng SP and Bau DT: Matrix metalloproteinase-1 genotype contributes to the risk of non-solid tumor in childhood leukemia. Anticancer Res 36: 5127-5132, 2016.

24 Pei JS, Hsu CM, Tsai CW, Chang WS, Ji HX, Hsiao CL, Miao CE, Hsu YN and Bau DT: The association of methylenetetrahydrofolate reductase genotypes with the risk of childhood leukemia in Taiwan. PLoS One 10: e0119776, 2015.

25 Pei JS, Chang WS, Hsu PC, Tsai CW, Hsu CM, Ji HX, Hsiao CL, Hsu YN and Bau DT: The association of flap endonuclease 1 genotypes with the risk of childhood leukemia. Cancer Genomics Proteomics 13: 69-74, 2016.

26 Lo WJ, Chang WS, Hsu HF, Ji HX, Hsiao CL, Tsai CW, Yeh SP, Chen CM and Bau DT: Significant association of interleukin-10 polymorphisms with childhood leukemia susceptibility in Taiwan. In Vivo 30: 265-269, 2016.

27 Chuang CL, Wang CH, Hsu CH, Hsiao CL, Chen GL, Yen ST, Li HT, Chang WS, Tsai CW, Wang SC and Bau DT: Contribution of double-strand break repair gene nijmegen breakage syndrome 1 genotypes, gender difference and smoking status to Taiwanese lung cancer. Anticancer Res 37: 2417-2423, 2017.

28 Yueh TC, Chou AK, Gong CL, Fu CK, Pei JS, Wu MH, Tsai CW, Chang WS, Hsiao CL, Yen ST, Li HT and Bau DT: The contribution of excision repair cross-complementing group 1 genotypes to colorectal cancer susceptibility in Taiwan. Anticancer Res 37: 2307-2313, 2017.
29 Yokoyama Y, Grunebach F, Schmidt SM, Heine A, Hantschel M, Stevanovic S, Rammensee HG and Brossart P: Matrilysin (MMP7) is a novel broadly expressed tumor antigen recognized by antigen-specific T-cells. Clin Cancer Res 14: 5503-5511, 2008.

30 Edman K, Furber M, Hemsley P, Johansson C, Pairaudeau G, Petersen J, Stocks M, Tervo A, Ward A, Wells E and Wissler L: The discovery of MMP7 inhibitors exploiting a novel selectivity trigger. ChemMedChem 6: 769-773, 2011.

31 Wieczorek E, Reszka E, Wasowicz W, Grzegorczyk A, Konecki $\mathrm{T}$, Sosnowski M and Jablonowski Z: $M M P 7$ and $M M P 8$ genetic polymorphisms in bladder cancer patients. Cent Eur J Urol 66: 405-410, 2014.

32 Basu S, Thorat R and Dalal SN: MMP7 is required to mediate cell invasion and tumor formation upon Plakophilin3 loss. PLoS One 10: e0123979, 2015.

33 Shao Q, Luo X, Yang D, Wang C, Cheng Q, Xiang T and Ren G: Phospholipase Cdelta1 suppresses cell migration and invasion of breast cancer cells by modulating KIF3A-mediated ERK1/2/beta- catenin/MMP7 signalling. Oncotarget 8: 2905629066, 2017.

34 Xu L, Hou Y, Tu G, Chen Y, Du YE, Zhang H, Wen S, Tang X, Yin J, Lang L, Sun K, Yang G, Tang X and Liu M: Nuclear Drosha enhances cell invasion via an EGFR-ERK1/2-MMP7 signaling pathway induced by dysregulated miRNA-622/197 and their targets LAMC2 and CD82 in gastric cancer. Cell Death Dis 8: e2642, 2017.

35 Qasim BJ, Ali HH and Hussein AG: Immunohistochemical expression of matrix metalloproteinase-7 in human colorectal adenomas using specified automated cellular image analysis system: a clinicopathological study. Saudi J Gastroenterol 19: 23-27, 2013.

36 Carruba G, D'Agostino P, Miele M, Calabro M, Barbera C, Bella GD, Milano S, Ferlazzo V, Caruso R, Rosa ML, Cocciadiferro L, Campisi I, Castagnetta L and Cillari E: Estrogen regulates cytokine production and apoptosis in PMA-differentiated, macrophage-like U937 cells. J Cell Biochem 90: 187-196, 2003.

37 Jain SK, Kannan K, Prouty L and Jain SK: Progesterone, but not 17beta-estradiol, increases TNF-alpha secretion in U937 monocytes. Cytokine 26: 102-105, 2004.

Received August 27, 2017

Revised September 20, 2017 Accepted September 22, 2017 